\title{
An innovative approach to tracking sediment transport along roads
}

\author{
Thomas Boving ${ }^{1,2, *}$, Tabatha Lewis $^{2}$, and Eko Siswoyo ${ }^{3}$ \\ ${ }^{1}$ University of Rhode Island, Department of Geosciences, Department of Civil and Environmental \\ Engineering. Kingston, RI 02881, USA \\ ${ }^{2}$ University of Rhode Island, Department of Geosciences, Kingston, RI 02881, USA \\ ${ }^{3}$ Universitas Islam Indonesia, Department of Environmental Engineering, Yogyakarta, Indonesia.
}

\begin{abstract}
A study of sediment transport was carried out in the New England area of the United States where large quantities of sediments and other debris accumulate along roads. These sediments are mostly transported by roadway runoff and stormwater drainage structures, where present, tend to concentrate them. However, polluted sediments might also find their way into ecologically sensitive areas. Our research aimed at tracking the transport of these sediments as they move along a road. Further, we attempted to quantify the rate by which the sediments were transported. Glass microbeads in the size range of sand were released as a tracer of sediment transport at six comparable locations. Over a period of 10 months, their movement was tracked using microscopy. Our results indicate that this type of tracer was successful in following along the sediment transport. More research is required to establish this new method under different stormwater runoff regimes or different roadside maintenance conditions.
\end{abstract}

\section{Introduction}

Roads are arteries for transporting a large number of cars, but their impervious surfaces also accumulate large quantities of sediment and other debris. Besides endangering motorist, these sediments eventually end up on the sides of roadways where they can degrade drainage systems, if present. Sediment laden runoff from roads can be minimized by either erosion control or sediment control best management practices (BMPs), such as retention ponds, bio-retention systems, or hydrodynamic separators, to name a few [1]. Temporary measures include silt fences, geosynthetic dikes, wattles, berms, bales, and rock check dams [2]. Large accumulations of sediments in BMP drainage structure can impact their function. If entirely overwhelmed, BMP clogging can cause street flooding. Along with increasing number of roads and motorists, these problems will be amplified by stronger storms predicted in most climate change models for the Northeast region of the USA. Also, the surfaces of sediment particles can attract contaminants, such as heavy metals or petroleum hydrocarbons [3-5], which than can get transported together.

*Corresponding author: boving@uri.edu 
These problems highlight the need for a better understanding where and how quickly road-side sediments travel, including what is the fate of the contaminants associated with those sediments. This understanding is critical in keeping our landscape and waterways environmentally healthy. It is therefore imperative that we study the transport behaviour of sediments along roadsides and understand the possible implications for human well-being.

In this study, we employed glass microbeads, which were released to a roadside environment, for tracing the rate of movement of sediments in the size fraction of sand. To the best of our knowledge, this approach has not been documented in the literature before. The insights generated in this study might aid in devising strategies to encounter the possibly problems associated with uncontrolled sediment accumulation in our infrastructure and the environment.

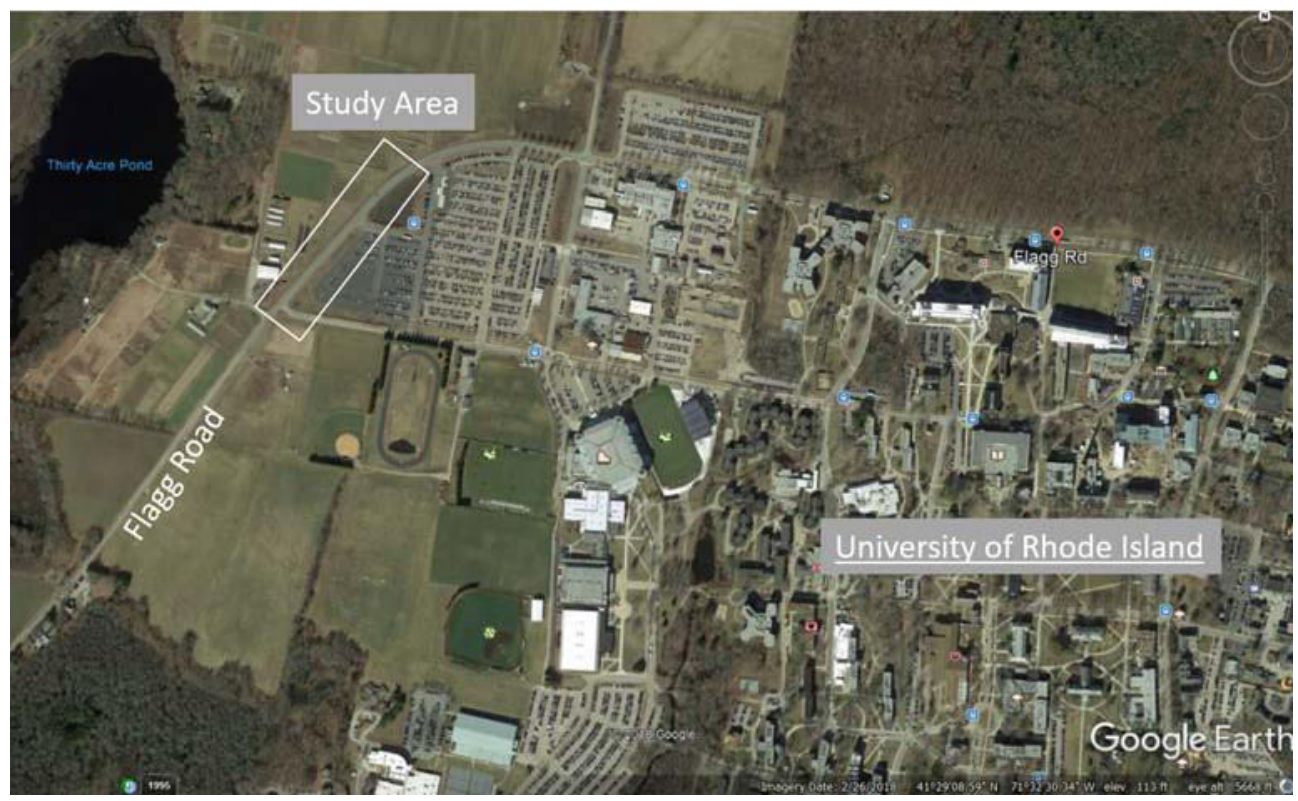

Fig. 1. The study site (white box) is located along Flagg Road/Plains Road on the campus of the University of Rhode Island, (Kingston USA). Source: Google Earth.

\section{Materials and Methods}

Study site: This project was carried out on the campus of the University of Rhode Island (URI), Kingston (USA). At six sites along Flagg Road/Plains Road (Figure 1), which serve as one of the main access roads to the URI campus, spherical glass beads of three different colors (white, blue, red) and sizes (ranging from $70 \mu \mathrm{m}$ to $425 \mu \mathrm{m}$ ) were released at wellmarked spots in equal numbers (12,900 beads per color) in July 2017 . For the following 10 months, the glass beads were allowed to naturally propagate by runoff and wind transport.

Materials and Methods: Sediment samples were collected at predetermined locations. Nine sample events were carried out. Each sediment sample (approximately 10 gr) was examined under a high-powered microscopy to identify and count manually the number and color of the beads (Figure 2). Select microbeads samples were analysed with a Field Emission Scanning Electron microscope (FE-SEM). After processing and reconstituting, the samples were returned to exactly the sample location in the field. The number of counted beads per sample location was tabulated and mapped over time using Surfer 15 software. 

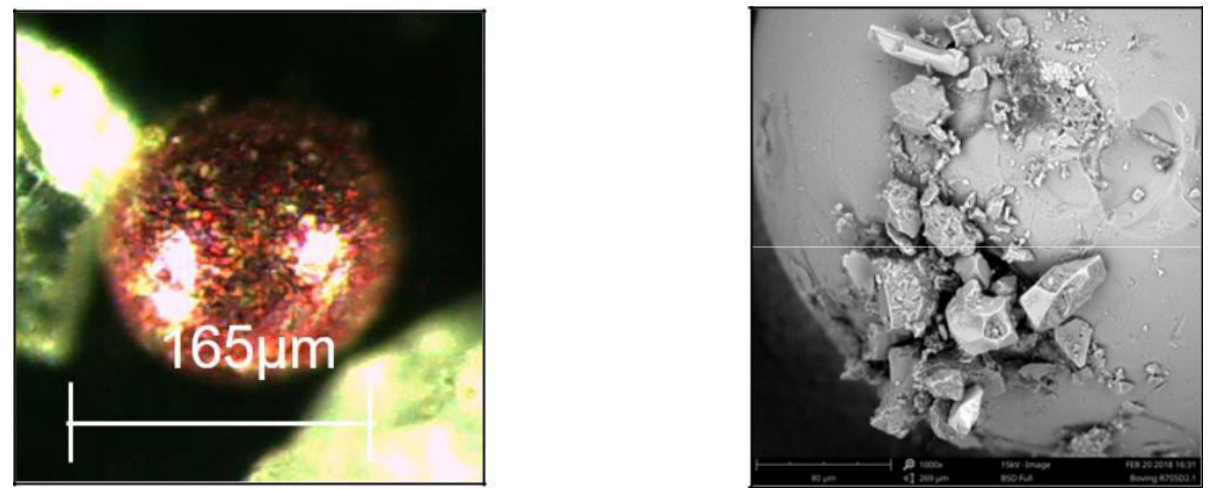

Fig. 2. Microscopy photograph of a red glass microbeads (Left) and FE-SEM image of a microbeads surface showing accumulation of unidentified debris (Right). Scale as shown. Source: Pictures taken by the authors.

\section{Results}

The contour maps created from the data collected at the six sites clearly illustrate that the glass microbeads were successfully tracked as they moved away from their release points. The example shown in Figure 3 indicate that the distance traveled over a 12 week period was approximately $10 \mathrm{~cm}$ to $30 \mathrm{~cm}$, as measured by the location of the plume's center of mass. This rate of transport is equivalent to an annual travel velocity of $0.4 \mathrm{~m}$ to $1.3 \mathrm{~m}$, assuming a constant rate of travel. Travel velocities of up to several meters per year were measured at another sites. The results demonstrate that microbeads can effectively trace the sediment flux both in terms of direction and magnitude.

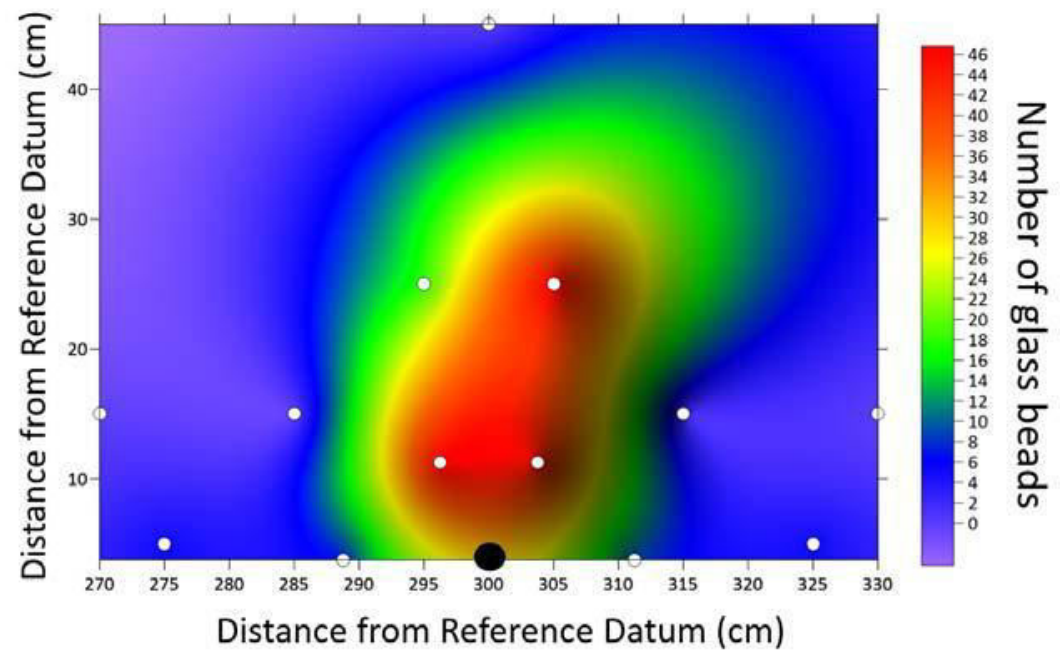

Fig. 3. Representative contour map created from the data collected at one of the six sites investigated. The distance traveled from the release point (black dot) was between $10 \mathrm{~cm}$ and $30 \mathrm{~cm}$ over a 12 week period, as measured by the plume's center of mass. The white circles represent the fixed sampling points. 
The direction of the plume movement was largely dictated by the micro-topography at each sampling site. That is, the center of mass of each plume followed the flow direction of the stromwater runoff, as expected. The distance of travel was greater for sites with steeper profiles, and therefore faster travel velocity of the flowing runoff.

The recoveries of microbeads were statistically evaluated for all sites, based on the kriging data generated by the Surfer software used in creating the contour maps (Figure 4). In general, the recovery estimates were high $(>75 \%)$, but varied over time, especially during the early stage of the experiment. These early variations were likely caused by insufficient data density used for the kriging extrapolation.

The FE-SEM images (Figure 2) revealed accumulation of debris on the surface of many of the glass spheres. These irregular shaped particles were examined by SEM-EDS for their elemental composition but the collected quantities were insufficient for qualification and quantification.

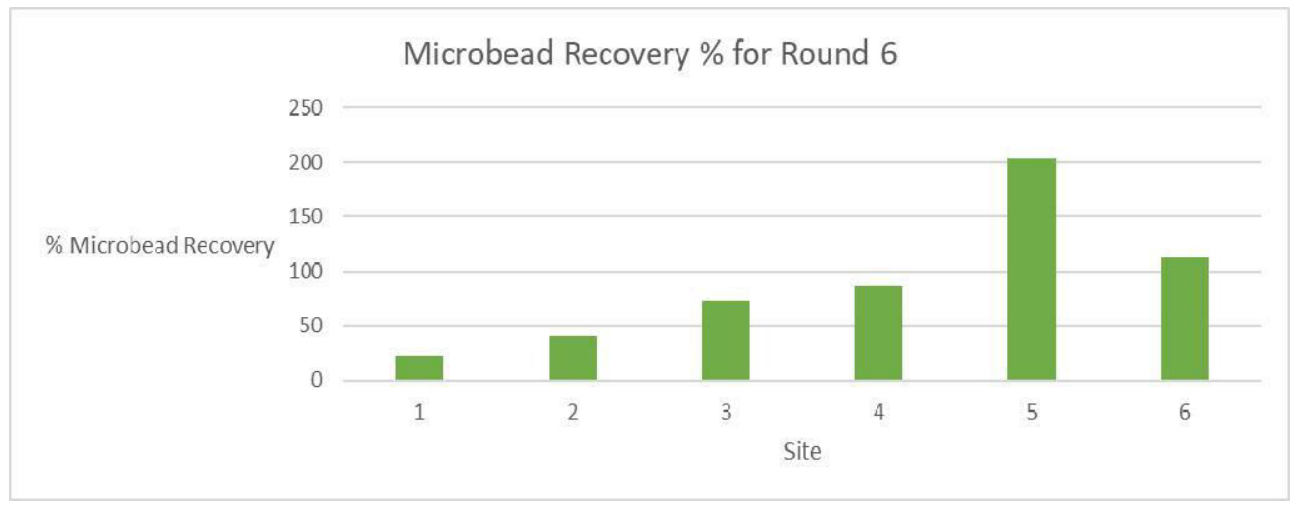

Fig. 4. As illustrated by the results from the sixth sampling round, the recovery of microbeads ranged from less than $50 \%$ to over $100 \%$. The comparative large variations were attributed to the method of extrapolation (kriging).

\section{Conclusions}

Glass microbeads can be used effectively as a tracer to predict the rate of transport of sediments adjacent to roads. The travel velocity of the sediment is site-dependent, as expected. The results of this field experiment indicate that the roadside sediments follow a predictable flow pattern that is governed by the local micro-topography. In general, studying colored glass microbeads is a new approach introduced herein for studying sediment transport along roadsides, or possibly other deposition environments. Further work is required to gain insights into how this technique performs under other environmental conditions, particularly higher or lower rainfall rates and roadside maintenance practices. Also, it needs to be studied how to identify and quantify contaminants that might be associated with the microbeads tracer.

\section{Acknowledgments}

This project was funded by the Rhode Island Department of Transportation, the University of Rhode Island Transportation Center, the Coastal Fellows Program, and the University of Rhode Island Geoscience Department. 


\section{References}

1. NCDOT - North Carolina Department of Transportation, 2013/ Erosion and Sediment Control Field Guide 2013 - Connect NCDOT. Currently available at https://connect.ncdot.gov/resources/roadside/FieldOperationsDocuments/fieldguid e2013 WEB.pdf

2. J. McFalls, M.-H. Li., A.B.R. Desai, ,2010. Roadside sediment control device evaluation program: Technical report. Publisher : Texas Transportation Institute.

3. J.M. Mudrea and J.J. Ney, 1986. Patterns of accumulation of heavy metals in the sediment of roadside streams Arch. Environ. Contam. Toxicol. 15: 489. https://doi.org/10.1007/BF01056560

4. J.H.Lee, K.W. Bang, L.H. Ketchum, J.S. Chloe, and M.J. Yu. 2002. First flush analysis of urban storm runoff. Science of the Total Environment 293(1-3), 163-175.

5. J. Liebens, 2001. Heavy metal contamination of sediments in stormwater management systems: the effect of land use, particle size, and age. Environmental Geology 41(3-4), 341-351. 